\title{
PERGELARAN WAYANG KRUCIL SELOPURO STRUKTUR KUASA ISLAM JAWA DALAM RITUAL NYADRAN
}

Rudi Irawanto

\begin{abstract}
Nyadran is an annual event in the village of Selopuro, Pitu District, Ngawi Regency, East Java. This event was held on every 10th Besar or 10 Dzulhijah which contained the salvation and performance of the krucil puppet. Activities in Nyadran and the performance of wayang krucil indicate the process of acculturation between authentic beliefs and Islamic spirituality. The acculturative process appears in the conscious prayer read out by the puppeteer and also in the puppet performance ritual. Prayers delivered at the slametan ritual and at the pre show influence the concept of pantheism, or the concept of manunggaling kawulo gusti. The concept of manuggaling kawulo gusti is one of the core of Javanese Islamic teachings.
\end{abstract}

Keywords: nyadran, wayang krucil, selopuro

\section{PENDAHULUAN}

Bersih desa atau nyadranmerupakan ritual peringatan hari kelahiran sebuah desa. Desa dal-am konteks ini merupakan kesatuan wilayah yang dibatasi dengan tanda-tanda geografis dan sosio kultural tertentu.Desa merupakan wilayah yang dipimpin seorang kepala dusun atau kamituwo. Aktivitas bersih desa merupakan upayamenjaga eksistensi kewilayahan melalui serangkaian kegi-atan sosial dan spiritual, sehingga setiap dusun akan memiliki cara yang berbeda-beda untuk merayakan bersih desa.

Nyadran juga menjadi ajang pertemuan semua warga desa dalam konteks spiritual. Peri stiwa yang dilakukan berdasarkan perhitungan numerologis atau kosmologis, sehingga waktu dan bentuk perayaannya tidak bisa diubah. Ketaatan pada pakem perayaan bersih desa diyakini akan membawa dampak positif bagi seluruh war-ga desa.

Selamatan nyadranlazimnya berisi beberapa rangkaian acara, yang dapat berbeda-beda di tiap-tiap wilayah. Rangkaian bersih desa terdiri dari selamatan desa, pementasan seni pertunjukan, dan prosesi doa.Slametan desa atau metri desa, difungsikan sebagai acara pembuka rang-kaian bersih desa. Slametan dalam tinjauan sosi-ologis merupakanwujud ekspresisocial dan kultu-ral dalam struktur social masyarakat Jawa. Slam-etan desa dimaknai sebagai pembersihan dari se-genap anasir-anasir jahat yang bersumber dari kekuatan mahkluk-makhluk halus (Geertz, 2017, 103).

Acara inti bersih desa adalah pementasan seni pertunjukan, yang bisa berbeda-beda di setiap wilayah. Perbedaan tersebut disebabkan ol-eh permitaan danyang desa yang bisa sangat ber-variatif. Danyang desa adalah figur gaib penunggu desa yang bermukin di punden desa atau makam pendiri desa. Seni pertunjukan sebagai acara inti dalam nyadrandipilih berdasarkan permintaan danyang desa, berdasarkan petunjuk gaib yang didapat dari sesepuh desa.

Acara terakhir dalam peristiwa bersih desa adalah pembacaan doa yang disertai dengan 
pembagian berkat atau makanan yang telah didoakan kepada para warga. Pada prosesi doa ini dilakukan dalam dua tahap, yaitu pembacaan nazar oleh dalang dan pembacaan doa oleh sesepuh desa atau para pemuka agama.Pemaduan antara kajat atau doa nazar dalam bahasa Jawa dengan doa dalam bahasa Arab menunjukkan proses aku-lturasi antara spiritulitas Jawa dan Islam.

Kasus di Desa Selopuro, Kecamatan Pitu, Kabupaten Ngawi menunjukkan fenomena akul-turasi budaya dalam konteks ritual nyadran atau bersih desa. Ritual nyadran dilaksanakan setiap tanggal 10 bulan besar atau bulan Dzulhijah dal-am system penanggalan Qomariyah.Berdasarkan penuturan sesepuh desa, ritual nyadran merupa-kan tradisi yang sudah dilaksanakan secara turun termurun semenjak abad ke 18. Prosesi nyadran di Desa Selopuro dilaksanakan sehari semalam, yang terdiri dari aktivitas pementasan wayang krucil, slametan desa, dan kegiatan pengajian.

Pementasan wayang krucil pada peristiwa Nyadran di Desa Selopuro, dapat dilihat dalam dua perspektif, yaitu perspektif sosial dan pers-pektif spiritual. Makalah ini akan menguraikan posisi pergelaran wayang dalam dua perspektif tersebut.

\section{DASAR TEORITIS}

\section{Teori Tafsir Kebudayaan}

Teori tafsir kebudayaan digunakan untuk melihat pola-pola interaksi budaya dalam struktur masyarakat. Teori tafsir budaya dalam pandangan Cliford Geertz melihat budaya sebagai sesuatu yang memiliki pola-pola tertentu yang berhu-bungan dengan sistem simbol dalam masyarakat tersebut. Pembacaan terhadap sistem simbol ini sebagai jembatan untuk mempelajari tingkah laku dan produk budayanya. Kebudayaan dapat dipa-hami dari sudut pandang pelaku budaya itu sen-diri. Kebudayaan bersifat semiotik yang selalu berhubungan dengan simbol yang telah dipahami serta dikenal dan diberlakukan bagi masyarakat yang bersangkutan. Teori tafsir kebudayaan dari Geertz ini digunakan untuk melihat pola-pola relasional dalam visualisasi wayang krucil sebagai simbol-sombol ke-budayaan.

Pendekatan atas kebudayaan harus dilakukan secara interpretatif, sehingga maknanya dapat dipahami. Simbol-simbol kebudayaan yang muncul dalam perilaku keseharian yang dipraktekan oleh kelompok masyarakat tertentu dalam lingkungan dan konteks historis tertentu. Menurut Geertz praktik etnografi bukan hanya permasalahan penggunaan metode-metode, menyeleksi dan melakukan wawancara, men-terjemahkan teks-teks dan hal-hal lain sesuai dengan buku metode penelitian. Pengetahuan yang diproduksi oleh seorang antropolog muncul dari sebuah penguraian (sekaligus pemak-naan/interpretasi) secara mendalam atas fenomena yang ditelitinya, sesuai dengan konsep thick description itu sendiri. Ciri dari paparan etnografis adalah interpretasi dari sebuah perbincangan sosial yang bersifat mikroskopis.

Menurut Geertz, proses rasionalisasi agama telah menimbulkan guncangan yang keras ter-hadap dasar-dasar tatanan sosial masyarakat. Ra-sionalisme agama mampu mengguncang dasar-dasar tatanan sosial masyarakat.Pada kasus di Bali, Geertz melihat guncangan yang terjadi seba-gai akibat situsi Bali yang terbuka pada pendi-dikan modern, bentuk pemerintahan modern dan kesadaran politis modern. Masyarakat Bali meng-alami perkembangan mendasar dalam menilai ke-budayaannya sendiri dan kebudayaan-kebudaya-an lainya.

Geertz memotret goncangan rasio-nalisme agama terhadap dasar-dasar tatanan sosial di Bali melalui sebuah pengalaman langsung menyaksikan pemuda-pemuda Bali berdebat menge-nai kesakralan agama. Perdebatan agama yang ter-jadi di antara para pemuda Bali itu kemudian su-dah dibentuk dalam pola-pola pemikiran rasional yang kemudian mengakibatkan krisis iman, han-curnya mitos-mitos 
dan terguncangnya dasar-dasar dalam bentuk sebenarnya.

Geertz memaparkan pengalaman penelitiannya yang lain, namun dalam konteks masyarakat pelaku kebudayaan yang sama, yaitu masyarakat kebudayaan Bali. Geertz menjelaskan dua hal, pertama adalah bagaimana caranya mendapatkan posisi strategis dalam sebuah penelitian agar dapat dihasilkan sebuah thick description.

Geertz menjelaskan, berdasarkan pengalamannya saat meniliti sabung ayam di Bali, bahwa untuk mendapatkan posisi yang strategis dalam penelitian (dalam arti diterima oleh obyek masyarakat yang diteliti) seorang peneliti harus melalui fase hembusan-angin. Fase hembusanangin adalah sebuah kondisi dimana seorang peneliti tidak dianggap ada oleh masyarakat yang ditelitinya. Geertz berusaha untuk menjelaskan tentang pentingnya metoda participant observation dalam sebuah penelitian antro-pologis yang mendalam.

Penjabaran Geertz atas permainan Sabung ayam dibali, dapat dipahami bahwa ritualritual ataupun komponen-komponen kebudayaan tidak dapat direduksi maknanya. Praktik thick description berarti melihat pola-pola hubungan kebudayaan masyarakat secara mendalam untuk dapat memahami arti khususnya di dalam kelompok masyarakat yang mem-praktekan dan menghayati nilai-nilai hubungan tersebut, dengan menggunakan sudut pandang responden.

\section{HASIL KAJIAN DAN PEMBAHASAN}

\section{Nyadran sebagai Peristiwa Kohesi Sosial}

Nyadran dapat dipahami sebagai ruang bertemunya tokoh-tokoh desa, sesepuh desa, pimpinan adat, dan masyarakat umum dalam satu konteks ritual. Tokoh-tokoh desa diisi oleh para pejabat desa, baik Lurah (kepala desa) atau Kamituwo (kepala dusun) dan para pejabat lainnya. Tokoh-tokoh ini dipilih atau oleh masyarakat setempat dalam satu forum pemilihan. Kedu-dukkan kepala desa diakui secara struktural seba-gai pejabat yang memiliki kewenangan formal un-tuk mengatur kehidupan desa, termasuk dida-lamnya kehidupan sosio budaya.

Peran kultural kepala desa atau kepala dusun sangat menentukan keberlangsungan proses nyadran yang akan dilakukan. Kegiatan nyadran bersifat swadaya warga desa, tetapi beban finansial pergelaran wayang krucil menggunakan anggaran dana dari kas desa. Besaran kas desa yang dibutuhkan pada proses pementasan tergan-tung pada kebijakan kepala desa. Pada konteks ini kepala desa mengambil peran sebagai pemegang kuasa sosial dan kultural.

Sesepuh desa merupakan pihak-pihak yang dianggap memiliki pengetahuan spiritual ya-ng lebih tinggi dari masyarakat biasa. Sesepuh tidak selalu berkonotasi usia tua, tepai lebih senior dalam dalam memahami ilmu-ilmu kejawaan atau ilmu-ilmu kejawen, meski pada beberpa tahun belakangan predikat sesepuh juga melekat pada tokoh-tokoh agama. Pada kasus di desa Selopuro, sesepuh desa juga seorang dalang wayang krucil. Dalang wayang krucil di Desa Selopuro merupakan dalang keturunan ke tujuh dari dalang wayang sebelumnya. Predikan sesepuh di-peroleh kerena masih menjalankan tradisi keja-wen dengan sangat baik, misalnya berpantang makan nasi pada bulan Suro atau Muharam, men-jalankan ritual tirakatan, dan menjadi tempat kon-sultasi spiritual bagi masyarakat sekitar.

Pada peristiwa nyadran, sesepuh desa me-njadi pihak yang mengantarkan upacara atau sla-metan desa menuju ruang-ruang sacral. Peran sesepuh desa sangat vital, karena mereka yang memiliki kuasa penuh menentukan waktu pelaksanaan nyadran dan pelengkapan yang harus disertakan pada ritual tersebut. Sesepuh desa merupakan pihak yang memegang kuasa spiritual yang menjadi penentu keberhasilan pelaksanaan ritual.

Posisi tokoh-tokoh agama pada beberapa tahun belakangan semakin menguat dan menun-jukan gejala menggeser peran sesepuh desa atau-pun tokoh-tokoh adat. Para agamawan, yang sep-enuhnya diisi golongan Jurnal Budaya Nusantara Vol. 2 No. 1 | 210 
muslim, berupaya mela-kukan purifikasi ajaran Islam di kawasan Selo-puro. Gerakan purifikasi Islam pada gilirannya mempengaruhi ritual nyadran yang telah dila-kukan. Pengaruh tersebut terlihat dari modifikasi aktivitas nyadran yang mulai diisi dengan kegiatan dakwah keagamaan. Pergeralan wayang krucil ya-ng pada era sebelumnya dilakukan selama satu hari dan satu malam, berkurang durasinya men-jadi hanya sehari saja. Pada malam hari nyadran diisi dengan kegiatan pengajian.

Prosesi nyadran di Desa Selopuro menunjukan peran tokoh-tokoh desa, yang dalam hal ini kepala desa dan kepala dusun, turut mempengaruhi bentuk ritual yang dilaku-kan.Kepala desa berupaya melakukan kompromi social antar pihak sesepuh dan kalangan agamawan. Nyadran tidak sekadar tindakan pele-starian budaya, tetapi juga menjadi ajang dialog social. Pihak tokohtokoh desa bekerja dalam konteks structural, sehingga kewenangan yang dimiliki dapat mempengaruhi struktur social yang telah ada. Kepala desa, sebagai tokoh desa, berupaya mencari jalan tengah agar kepentingan budaya dan relegius tetap terjaga.

Peristiwa nyadran di Desa Selopuro pada kurun sebelumnya hanya dilangsungkan di punden desa di depan Makam Sentono. Makam Sentono merupakan makam pendiri desa, yang merupakan salah satu abdi dalem Keraton Surakarta. Pada perkembangan berikutnya nyadran dilakukan di dua lokasi, yaitu di punden desa dan di rumah kepala dusun (kamituwo). Pemecahan ritual nyadaran menjadi dua lokasi dapat dimaknai sebagai upaya kepala desa untuk menjaga kohesi social. Nyadran agar dimaknai sebagai upaya me-njaga kelestarian tradisi yang telah ada di Desa Selopuro, tetapi juga memperhatikan kepen-ti-ngan kelompok kalangan santri konservatif yang menginginkan ritual nyadran diberi nuansa rele-gius.Pada ritual nyadran pertemuan kedua kel-ompok tersebut berjalan dengan baik. Per-gelaran wayang krucil tetap dilangsungkan tetapi penga-jian juga dilaksanakan.

\section{Islam Jawa pada Nyadran}

Islam Jawa merupakan istilah yang merujut pada pola sinkretisme Islam dengan kepercayaan local (Jawa). Pola-pola penyatuan kepercayaan lokal (Jawa) dalam kepercayaan muslim di Indonesia, memiliki beberapa model. Model yang paling banyak bersifat akulturatif, seperti yang diungkapkan Geertz (2017) dengan menyebut sebagai komunitas abangan. Geertz menyebut proses akulturasi sebagai ruang yang mampu menumbuhkan kepercayaan tersendiri yang berisi keyakinan terhadap numerology, dunia gaib, dan beberapa tradisi ritual yang tumbuh subur di beberapa wilayah pedesaan di Jawa. Bahasan ter-hadap Islam Jawa juga diutarakan oleh Mulder (1999), yang mengutarakan tentang lokalisasi agama-agama asing di Jawa, khususnya Islam. Agama-agama pendatang, khususnya Islam, dinilai mampu mewadahi beberapa konsep keper-cayaan asli sehinga Islam mampu diterima dengan mudah oleh masyarakat Jawa. Tradisi menjadi ruang interaksi dari beragam keyakinan dalam Islam. Islam tampil dalam wajah sinkretik.

Sinkretisasi Islam dan tradisi local juga diutarakan oleh Woodward (1991), sinkretisasi tidak terjadi melalui dialog Islam dan tradisi Hindu, tetapi Islam dengan tradisi local yang sesuai (compatible). Islam Jawa bukan merupakan Isam yang bersifat animistic dan sinkretik, tetapi Islam yang kontekstual dan berproses secara akulturatif. Ritual slametan sebagai salah satu ekspresi budaya Islam Jawa secara kontekstual dapat dijumpai pada sumber tekstualnya (Syam, 2017:21). Ritual nyadran merupakan salah satu ekspresi budaya Islam Jawa yang masih dapat dijumpai dibeberapa wilayah di Jawa Timur.

Ritual Nyadran di Desa Selopuro menjadi salah satu gambaran proses akulturatif yang masih berlangsung hingga saat ini. Para tokoh desa dan sesepuh desa berupaya melakukan kompromi antara adat dan agama, sehingga dicapai jalan tengah yang dapat 
diterima oleh masing-masing pihak. Dalang wayang krucil yang mewakili sepepuh desa, dapat berkompromi dengan kepala dusun yang mewakili tokoh muslim.

Nyadran di Desa Selopura bergeser ke arah pola-pola akuturatif antara keyakinan asli dan Islam. Bentuk akulturasi yang paling kelihatan terdapat pada pelaksanaan slametan. Doa yang dibacakan merupakan akulturasi Jawa dan Islam. Pada slametan Nyadran, dalang membacakan doa pengantar dalam bahasa Jawa, yang berbunyi:

Sepindahipun maleh mirsani para nabi lan para wali. Kangge mirsani wilujengan wilujengo serinten sadalune...

Sepindahipun mirsani rejeki, bopo toyo dalasan api

Sepindahipun malih mirsani bethoro gonggo , bethoro Giri, Nabi ilyas bagindo khilir. bethoro gonggo kang rumekso wonten nggegono, Bethoro Giri kang Rumekso wonten toyo. Nabi Ilyas manungso jaban pasowan utawi punden ingkang wajib dipun garap.....

Sepindah malih cikal bakal punden...ingkang mannggen kiblat sekawan gangsal sami dipun lenggahi....

Doa pengantar tersebut menyebut pihakpihak yang harus dihormati, yaitu 1) Nabi dan wali penyebar agama Islam ditanah Jawa, 2) Anasir-anasir penguasa kegaiban, 3) Penguasa penjuru alam, dan 4) pendiri desa. Penghormatan dalam konteks nyadran dapat dilihat sebagai upaya dialogis antara kekuatan spiritual, dalam paradigm budaya Jawa, yaitu para penguasa alam gaib dengan kekuatan spitual dalam dunia Islam Jawa, yaitu para wali

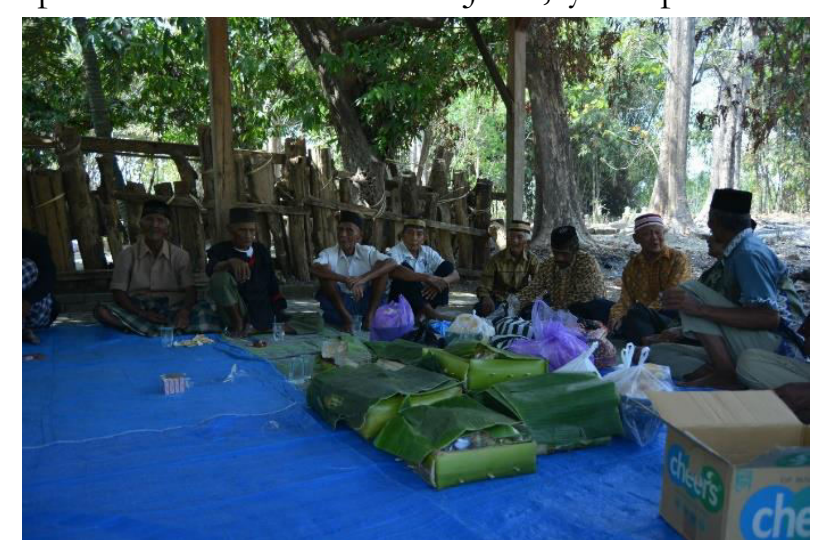

dan nabi-nabi. Peristiwa yang mengukuhkan dialog Islam dan budaya local.

Gambar Ritual Nyadran di Desa Selopuro (sumber: data pribadi)

Dialog yang sering dimaknai sebagai proses akulturatif dan masih tetap berlangsung hingga hari ini.Sejarah perkembangan Islam di pulau Jawa sedikit berbeda dengan persebaran Islam di Sumatra. Islam di Jawa tersebar melalu jalur Gujarat, bukan dari jalur Hadramaut seperti yang diterjadi di Sumatra. Bukti arkeologis menu-njukan Islam pada abad ke 7 sudah berkembang di kawasan Asia Tenggara, makam di Leran Gre-sik merupakan salah satu makam Islam tertua di Asia Tenggara. Makam tersebut menggunakan huurf Arab bergaya Kufi yang diduga berasal dari Gujarat (Ambary, 1998:54).

Islam yang berkembang melalui jalur Gujarat diduga bersentuhan dengan konsep tasawuf yang berkembang di wilayah tersebut. Tasawuf sendiri memiliki beberapa fase perkembangan, salah satu fase yang popular, ber-kembang di abad ke III dan ke IV Hijriah, yaitu ajaran dari Abu Yazid al Bustham (261 H) tentang konsep kefanaan (Syukur, 1999:33). Tasawuf ter-sebut berkembang menjadi konsep Wahdatul Wujud, yang kemudian menyebar hingga ke ka-wasan Asia Tengara. Konsep ini menjadi salah wujud Pantheisme dalam Islam di Jawa, yang dikenal dengan sebutan manunggaling kawulo gusti.

Konsep manunggaling kawulo gusti pada banyak kasus dilihat sebagai salah satu karakter utama Islam jawa. Konsep ini tergambar dalam ritual Nyadran yangdilaksanakan di Desa Selopuro Kecamatan Pitu Kabupaten Ngawi. Doa pe-ngantar yang dilakukan dalang menyebut bebe-rapa komponen yang tidak dikenal dalam konsep doa-doa dalam Islam.Sebutan para danyang da-lam ritual slametan merupakan salah petanda hadirnya konsep Islam Jawa dalam ritual tersebut. 


\section{Wayang Krucil dalam Nyadran}

Puncak acara aktivitas nyadran di Desa Selopuro adalah pementasan wayang krucil. Pementasan wayang krucil dilaksanakan sebagai respon atas permintaan danyang desa yang diterima para sesepuh melalui petanda-petanda gaib. Pementasan ini menjadi aktivitas yang harus diikuti oleh seluruh warga desa, karena per-mintaan danyang desa dianggap sebagai kewajiban yang memiliki konsekswensi social. Peristiwa gagal pa-nen dan bencana desa dapat dihubungkan peri-stiwa Nydran dan pementasan wayang krucil yang dilakukan.

Kesalahan dalam menentukan tanggal, hingga kesalahan dalam pemilihan lakon dapat membawa konsekwensi social yang berakibat fatal bagi seluruh masyarakat. Pementasan wayang krucil menjadi inti dari aktivitas nyadran. Pementasan ini dilaksanakan menjalang siang dan ber-akhir sebelum ashar. Waktu pementasan yang sama dengan pementasan adegan murwokolo pada wayang kulit.

Pementasan wayang krucil pada ritual nyadran ini didahului dengan pembacaaan doa oleh dalang, yang berhubungan kelancaran pementasan yang dilakukan. Doa yang dibacakan berhubungan dengan permintaan doa restu kepa-da nabi, para wali dan dayang desa . Pembacaaan doa ini berlangsung sekitar 10 menit dan diakhiri dengan pembagian makanan (ber-kat) kepada seluruh kru wayang. Kru wayang berjumlah sekitar 6 orang termasuk dalang. Ritual selamatan ini dilaksanakan untuk menjaga hubungan biak dengan danyang desa.

Dalang memiliki keyakinan bahwa hubungan baik dengan danyang desa akan memperlancar pertunjukan wayang akan dila-kukan. Hubungan baik tersebut dilakukan dengan memberi suguhan berupa sesajen, yang berisi air sumber setempat dan kemenyan arab, yang disajikan bersama ingkung ayam, bubur putih, sayur pado-moro (kluwih dan kacang), telur ayam kampung, nasi gurih, dan polo pendem atau buah yang tert-anam dalam tanah misalnya ketela dan ubi.

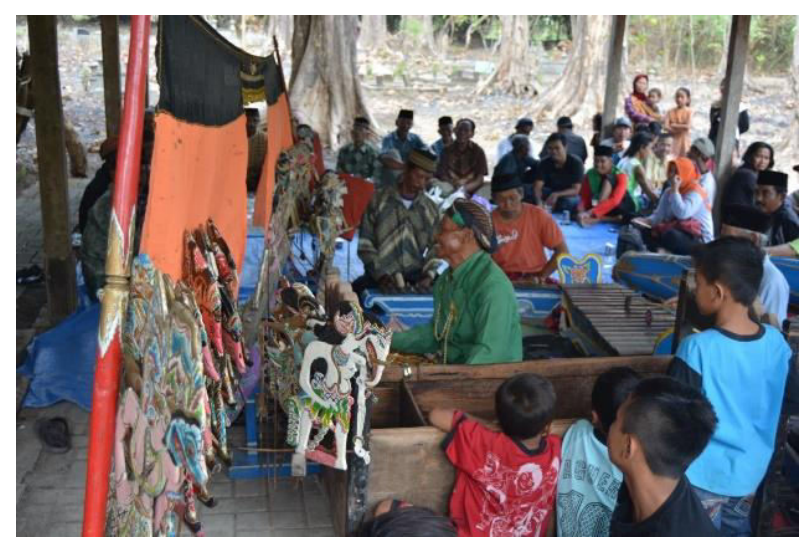

Gambar Pentas wayang krucil di depan makam Sentono desa Selopuro (sumber: data pribadi)

Pembakaran kemenyan diyakini sebagai media untuk bertemu para danyang desa, yang akan memberi restu sehingga prosesi pergelaran tidak akan terganggu. Dalang dan sesepuh desa menyakin bahwa restu danyang akan ditunjukan melalui tanda-tanda alam misalnya hembusan an-gin yang tidak terlalu kencang. Prosesi pementasan wayang krucil selalu didahului dengan ritual permohonan ijin kepada danyang desa melalui doa-doa pra pementasan.

Proses inti dari pergelaran wayang krucil adalah pementasan setelah rangkain doa-doa dan pembagian sesajen kepada kru dilakukan. Ayam ingkung yang telah didoakan akan dibagikan kepada para kru untuk dimakan sebelum peme-ntasan berlangsung. Peristiwa simbolis permu-laan penyatuan dalang dan kru dengan kekuatan adi kodrati.

Pada tahap berikutnya adalah pementasan wayang dengan lakon yang telah disepakati sebe-lumnya, meskipun para dalang sering kali mem-iliki kewenangan untuk menentukan lakon yang ia sukai. Para dalang sudah memiliki pandauan, ce-rita-cerita yang sesuai untuk ritual nyadran atau bersih desa. Cerita-cerita yang dihindari biasanya berhubungan dengan ber-akirnya suatu kerajaan atau hancurnya satu wilayah tertentu, misalnya bedahing Majapahit atau bedahing demak.

Para dalang menyakini bahwa pemilihan crita ini berkorelasi dengan keseimbangan kos- 
mos. Peristiwa pertunjukan wayangkurcil dapat dilihat sebagai peristiwa bertemunya Tuhan dan mahkluknya. Dalang dihadirkan sebagai representasi dzat Tuhan yang memiliki kew-enangan menggerakkan mahkluk-mahkluknya. Pertunjukan wayang krucil menjadi media iso-teris. Pertunjukan wayang krucil diakhiri deng-an selamatan desa yang diikuti oleh beberapa perwakilam warga desa.

\section{KESIMPULAN}

Peristiwa nyadran di Desa Selopuro, Kecamatan Pitu, Kabupaten Ngawi, merupaka ritual yang diadakan setahun sekali setiap tanggal 10 Suro. Pada kedua peristiwa tersebut menunjukkan bahwa terjadi peristiwa akulturatif antara spitualitas Jawa dan Islam. Proses akulturatif yang ditunjukan pada ritual selametan dan pada proses pementasan wayang krucil. Doa yang disam-pai-kan dalang pada ritual tersebut menunjukkan adanya paham manunggaling kawulo gusti, kon-sep yang memandang bahwa dzat Tuhan mewu-jud dalam diri mahkluknya.

Konsep manunggaling kawulo gusti merupakan salah satu ekspresi Islam Jawa. Islam Jawa merupakan salah satu gerakan spiritual yang menggabungkan keyakinan dalam agama Islam dengan kepercayaan local. Kuasa Islam Jawa da-lam nyadran dapat dijumpai pada ke 2 peristiwa tersebut, sehingga setiap warga desa tidak berani untuk mengubah tatanan yang telah terbentuk.

\section{DAFTAR PUSTAKA}

Ambary, Hasan Muarif
1991 Peranan Cirebon Sebagai Pusat Perkembangan dan Penyebaran Islam. Artikel dalam Cirebon Sebagai Bandar Jalur Sutera. Jakarta: Departemen Pendi- dikan dan Kebudayaan RI.

Ambary, Hasan Muarif
1998 Menemukan Peradaban Jejak Arkeologis dan Historis Islam di Indonesia. Jakarta: Logos.

Geertz, Cliford

1992 Politik Kebudayaan. Yogyakarta: Kanisius.

Geertz, Cliford

2015 Agama Jawa Abangan Santri Proyayi dalam Kehidupan Jawa. Depok: Komunitas Bambu.

Geertz, Cliford

2016 Tafsir Kebudayan. Yogyakarta: Kanisuis

Hadi, Y. Sumandyo

2006 Seni dalam Ritual Agama.Yogyakarta: Pustaka.

Koentjaraningrat

1994 Kebudayaan Jawa. Jakarta: Balai Pustaka.

Lombard, Denys

1996 Nusa Jawa Silang Budaya Batas-Batas Pembaratan. Jakarta: Gramedia Pustaka Utama.

Magnis-Suseno, Frans

1995 Wayang Dan Panggilan Hidup Manusia. Jakarta: Gramedia Pustaka Utama.

Magnis-Suseno, Frans

1996 Etika Jawa Sebuah Analisa Falsafi. Tentang Kebijaksanaan Hdup Orang Jawa. Jakarta: Gramedia Pustaka Utama.

Piliang, Yasraf Amir

2010 Post Realitas Realitas Kebudayaan dalam Era Post-metafisika. Yogyakarta: Jalasutera.

Pranowo, Bambang

2011 Memahami Islam Jawa. Jakarta: Pustaka Alvabet

Jurnal Budaya Nusantara Vol. 2 No. 1 | 214 
Prijotomo, Josep

1992 Ideas And Forms Of Javanese Architecture. Yogyakarta: Gadjah Mada University Press.

Rahardjo, Supratikno

2011 Peradaban Jawa dari Mataram Kuno sampai Majapahit akhir. Jakarta: Komunitas Bambu.

Sumardjo, Jakob

2014 Estetika Paradoks. Bandung: Kelir.

Susetya, Wawan

2007 Dhalang, wayang dan gamelan mengungkap nilai-nilai filosofi dibalik pementasan wayang pada masyarakat Jawa. Yogyakarta: Narasi.

Syam, Nur

2011 Islam Pesisir. Jakarta: LKIS

Wibowo, Anjar Mukti

2015 Sejarah Kesenian Wayang Timplong Kabupaten Nganjuk dalam Jurnal Aga-stya Vol 5 No 2 Juli 2015

Widadi, Subur

2016 .Membaca wayang dengan Kacamata Islam. Sukoharjo:CV Farisma Indonesia.

Woodward, Mark R

1999 Islam Jawa Kesalehan Normatif Versus Kebatinan. Yogyakarta: LKIS.

Yudoseputro, Wiyoso

2008 Jejak jejak Tradisi Bahasa Rupa Indonesia Lama. Jakarta: Yayasan Seni Visual Ind-onesia.

Zoemulder, P.J

1990 Manunggaling Kawula Gusti Patheisme Dan Monoisme Dalam Sastra Suluk Jawa. Jakarta: Gramedia Pustaka Utama.
1939 Wajang Poerwa. Yogyakarta: Drukerij Mataram. 